\title{
Analisa Heat Transfer Alat Pasteurisasi Susu
}

\author{
Maonika Silviani Prasetyo \\ Teknik Mesin, Universitas Nusantara PGRI Kediri \\ E-mail: smaonika@gmail.com
}

\begin{abstract}
Abstrak
Dalam menaikkan tingkat kesehatan masyarakat, salah satu solusinya adalah mengkonsumsi susu yang higienis dengan proses pasteurisasi susu yang berfungsi untuk mensterilkan susu sehingga menjadi susu yang siap konsumsi. Penelitian ini bertujuan untuk mengetahui heat transfer yang terjadi pada alat pasteurisasi. Penelitian ini menggunakan metode ekperimen untuk mendapatkan data aktual dari alat pasteurisasi susu serta temperatur dari susu sebelum masuk pemanas hingga keluar pendingin, temperatur air pemanas dan temperatur air pendingin. Metode perhitungan yang digunakan untuk mencari heat transfer adalah Log Mean Temperature Different (LMTD) dan Effectiveness - Number of Transfer Unit (NTU).Dari perhitungan yang telah dilakukan, nilai heat transfer proses pemanasan susu yaitu sebesar 101,7 watt dan 76,68 watt dengan temperatur air pemanas $98,1^{\circ} \mathrm{C}$ sehingga menghasilkan efisiensi sebesar $83,6 \%$ dan $83,7 \%$. Sedangkan untuk nilai heat transfer proses pendinginan susu yaitu sebesar 102,68 watt dan 120,2 watt dengan temperatur air pendingin $15^{\circ} \mathrm{C}$ sehingga menghasilkan efisiensi sebesar $82,4 \%$ dan $83,2 \%$.
\end{abstract}

Kata Kunci: efektivitas, pasteurisasi susu, perpindahan panas

\begin{abstract}
In raising the level of public health, one solution is consume hygienic milk with a milk pasteurization process to sterilize milk so that it is ready for consumption. This research aims to determine the heat transfer that occurs in the pasteurizer. This study use an experimental method to obtain actual data from milk pasteurizer and the temperature of the milk before entering heater to come out cooling process, water heater temperature and water cooler temperature. The calculation method used to find the heat transfer is Log Mean Temperature Different (LMTD) and Effectiveness Number of Transfer Unit (NTU). From the calculations that have been done, the value of the heat transfer heating process milk that is equal to 101.7 watts and 76.68 watts with the heating water temperature $98.1{ }^{\circ} \mathrm{C}$ with the result of efficiency of $83.6 \%$ and 83.7\%. While for the value of heat transfer milk cooling process that is equal to 102.68 watts 120.2 watts with cooling water temperature of $15^{\circ} \mathrm{C}$ so as to produce efficiency amounted to $82.4 \%$ and $83.2 \%$.
\end{abstract}

Keywords: effectiveness, heat transfer, milk pasteurization

\section{PENDAHULUAN}

Indonesia merupakan salah satu negara dengan populasi penduduk yang besar di dunia. Pada tahun 2019, diproyeksikan kepadatan penduduk di Indonesia mencapai 268.074 ribu jiwa [1]. Kepadatan penduduk yang tidak merata dapat 
menimbulkan berbagai masalah. Salah satu kemungkinan yang terjadi ketika kepadatan penduduk terlalu tinggi adalah rendahnya tingkat kesehatan dari penduduk setempat. Salah satu yang yang dapat meningkatkan kesehatan masyarakat yaitu konsumsi susu. Untuk konsumsi susu segar sebaiknya tidak langsung diminum karena terdapat bakteri yang tercampur baik dari udara maupun dari kontak lingkungan yang lain. Alangkah baiknya apabila susu segar tersebut melalui proses penanganan terlebih dahulu yaitu dengan proses pasteurisasi susu. Pasteurisasi susu merupakan tindakan pemanasan (heat transfer) susu hingga suhu tertentu dan dipertahankan pada suhu tersebut selama waktu yang sudah ditentukan. Tujuan dari proses pasteurisasi ini adalah untuk menghilangkan bakteri yang merugikan seperti mikroorganisme patogen serta sebagian besar mikroorganisme pembusuk karena diketahui kuman penyakit seperti TBC (Tuberculosis) dan tifus juga dapat berasal dari susu [2].

Dalam penelitian kali ini lebih terfokuskan pada proses heat transfer yang terjadi pasa proses pasteurisasi susu. Mengetahui proses pasteurisasi susu itu sendiri mulai dari masuknya susu murni ke pemanas, masuk ke dalam pendingin dan terakhir siap konsumsi ataupun dikemas dengan variasi debit susu yang berbeda.

\section{METODE PENELITIAN}

Seluruh rangkaian penelitian dan pengambilan data dan semua alat siap untuk digunakan. Pada dasarnya pengujian fungsional alat ini dilakukan untuk mengetahui kerja masing - masing komponen dan memastikan komponen tersebut bekerja dengan baik, menyusun dan penulisan laporan menggunakan dua metode serta pengumpulan atau pengambilan data.

\section{a. Metode Studi Literatur}

Pada tahapan studi literatur penulis mencoba memahami proses heat transfer pada alat pasteurisasi susu. Dengan studi literatur ini, penulis dapat mencari kemungkinan yang terjadi sehingga diketahui dugaan awal bagaimana proses heat transfer itu bisa terjadi sehingga dapat menyusun hipotesa. Studi literatur ini dilakukan pada 
perpustakaan dan diskusi dengan dosen pembimbing. Untuk menambah referensi, media internet juga digunakan sebagai sumber pengetahuan.

\section{b. Metode Observasi}

Dalam perhitungan heat transfer, penulis membutuhkan data-data tertentu baik secara teoritis maupun aktual, sehingga mampu menghasilkan perhitungan yang sesuai dan akurat. Data yang diambil adalah data spesifikasi alat pasteurisasi susu, desain alat pasteurisasi susu, dan data properties aktual dari hasil percobaan. Dengan spesifikasi desain alat pasteurisasi susu adalah pemanas dan pendingin susu berbentuk tabung dan di dalam tabung terdapat pipa berbahan tembaga. Akan tetapi sebelum data itu diambil diperlukan persiapan terlebih dahulu untuk merancang suatu pengumpulan data. Langkah awal yaitu observasi lapangan terlebih dahulu, sehingga kita mampu mengetahui data apa saja yang diperlukan dan dimana kita mampu mendapatkan data tersebut. Kemudian setelah itu, baru dilakukan diskusi dengan pihak-pihak yang mampu memberikan informasi tentang data yang dibutuhkan.

Jenis analisis data yang digunakan dalam penelitian ini adalah perhitungan menggunakan Log Mean Temperature Different (LMTD) dan Effectiveness - Number of Transfer Unit (NTU) [3]. Analisa berupa data variabel yang diamati langsung dalam penelitian ini adalah pengujian temperatur susu keluar pemanas dan temperatur susu keluar pendingin. Yang akan diuji dan diamati dalam penelitian ini adalah proses heat transfer yang terjadi selama proses pasteurisasi susu. Alat penukar kalor (heat exchanger) menjadi alat yang paling esensial dalam proses pasteurisasi karena kebutuhan panas yang digunakan untuk pasteurisasi dihasilkan oleh alat penukar panas[4].

Setelah melakukan percobaan pemanasan terhadap susu menggunakan alat pasteurisasi susu, dilakukan deskripsi hasil percobaan untuk mengetahui heat transfer pada proses pasteurisasi susu. Selain itu analisis juga dilakukan sebagai antisipasi jika terdapat gangguan yang ditimbulkan pada alat pasteurisasi susu. Jika temperatur susu yang masuk 
ke dalam tabung pemanas dan masuk kedalam tabung pendingin sesuai dengan jumlah pemanasnya dan pendinginnya maka akan menghasilkan susu pasteurisasi yang siap konsumsi.

Beberapa penelitian pendahulu menyebutkan bahwa untuk melakukan uji karakteristik perpindahan panas pada double pipe heat exchanger (segmen pemanasan) dilakukan dengan pengamatan pengaruh variasi laju alir parameter terhadap parameter hi, ho, dan U. Ketiga parameter tersebut berbanding lurus dengan nilai $\mathrm{N}_{\mathrm{Re}}$ dengan kualitas susu tidak terdenaturalisasi. Selain itu, penelitian lain yang dilakukan oleh Wahyuni, menyebutkan bahwa waktu tinggal pasteurisasi optimum 17,5 detik, dengan hasil susu yang secara subtansi tidak berubah dan kandungan bakteri patogen $17.500 \mathrm{sel} / \mathrm{ml}$, yang dicapai pada laju alir $112,5 \mathrm{ml} / \mathrm{jam}[5]$.

\section{HASIL DAN PEMBAHASAN}

Prinsip kerja pasteurisasi adalah perlakuan panas yang diberikan pada bahan baku dengan suhu dibawah titik didih. Teknik ini digunakan untuk mengawetkan bahan pangan yang tidak tahan suhu tinggi, misalnya susu. Pasteurisasi tidak mematikan semua mikroorganisme, tetapi hanya yang bersifat patogen dan tidak membentuk spora. Oleh sebab itu, pasteurisasi ini sering diikuti dengan teknik lain, misalnya pendinginan atau pemberian gula dengan konsentrasi tinggi. Produk hasil pasteurisasi bisa disimpan pada suhu kamar, hanya bertahan 1 sampai 2 hari, sedang jika disimpan pada suhu rendah dapat tahan 1 minggu.

Pasteurisasi memiliki beberapa tujuan, yaitu:

a. Untuk membunuh bakteri patogen

b. Untuk memperpanjang daya simpan bahan atau produk

c. Dapat menimbulkan cita rasa yang lebih baik pada produk

d. Pada susu proses ini, dapat menonaktifkan enzim fosfatase dan katalase yaitu enzim yang membuat susu cepat rusak.

Hasil perhitungan dari data percobaan dengan temperatur masuk susu ke pemanas dengan variasi yang berbeda dapat dilihat pada tabel berikut: 
Tabel 1. Hasil Perhitungan Proses Pemanasan

\begin{tabular}{|c|c|c|c|}
\hline No & & $\begin{array}{c}\text { Proses Pemanasan }\left(T_{c o}\right. \\
\left.=90^{\circ} \mathrm{C}\right)\end{array}$ & $\begin{array}{c}\text { Proses Pemanasan }\left(T_{c o}\right. \\
\left.=96,9^{\circ} \mathrm{C}\right)\end{array}$ \\
\hline 1 & $\dot{\mathrm{m}}_{c}$ & $63,9009 \times 10^{-6} \frac{\mathrm{kg}}{\mathrm{s}}$ & $63,8 \times 10^{-6} \frac{\mathrm{kg}}{\mathrm{s}}$ \\
\hline 2 & $h_{i}$ & $325,122 \frac{\mathrm{W}}{\mathrm{m}^{2} \cdot \mathrm{K}}$ & $326,89 \frac{\mathrm{W}}{\mathrm{m}^{2} \cdot \mathrm{K}}$ \\
\hline 3 & $h_{o}$ & $18,7 \frac{\mathrm{W}}{\mathrm{m}^{2} \cdot \mathrm{K}}$ & $19,03 \frac{\mathrm{W}}{\mathrm{m}^{2} \cdot \mathrm{K}}$ \\
\hline 4 & $\mathrm{U}$ & $17,24 \frac{\mathrm{W}}{\mathrm{m}^{2} \cdot \mathrm{K}}$ & $17,52 \frac{\mathrm{W}}{\mathrm{m}^{2} \cdot \mathrm{K}}$ \\
\hline 5 & $\Delta T_{L M}$ & $28,18 \mathrm{~K}$ & $20,36 \mathrm{~K}$ \\
\hline 6 & $\mathrm{q}$ & $101,7 \mathrm{Watt}$ & $76,68 \mathrm{Watt}$ \\
\hline 7 & $\mathrm{NTU}$ & 13,72 & 13,95 \\
\hline 8 & $\varepsilon$ & $83,6 \%$ & $83,7 \%$ \\
\hline
\end{tabular}

Hasil perhitungan dari data percobaan dengan temperatur masuk susu ke pendingin dengan variasi yang berbeda dapat dilihat pada tabel berikut:

Tabel 2 Hasil Perhitungan Proses Pendinginan

\begin{tabular}{|c|c|c|c|}
\hline No & $\begin{array}{c}\text { Proses Pendinginan } \\
\left(T_{h o}=26,5^{\circ} \mathrm{C}\right)\end{array}$ & $\begin{array}{c}\text { Proses Pendinginan } \\
\left(T_{h o}=31,3^{\circ} \mathrm{C}\right)\end{array}$ \\
\hline 1 & $\dot{\mathrm{m}}_{c}$ & $63,8 \times 10^{-6} \frac{\mathrm{kg}}{\mathrm{s}}$ & $63,77 \times 10^{-6} \frac{\mathrm{kg}}{\mathrm{s}}$ \\
\hline 2 & $h_{i}$ & $368,4 \frac{\mathrm{W}}{\mathrm{m}^{2} \cdot \mathrm{K}}$ & $371,9 \frac{\mathrm{W}}{\mathrm{m}^{2} \cdot \mathrm{K}}$ \\
\hline 3 & $h_{o}$ & $17,46 \frac{\mathrm{W}}{\mathrm{m}^{2} \cdot \mathrm{K}}$ & $20,65 \frac{\mathrm{W}}{\mathrm{m}^{2} \cdot \mathrm{K}}$ \\
\hline 4 & $\mathrm{U}$ & $16,28 \frac{\mathrm{W}}{\mathrm{m}^{2} \cdot \mathrm{K}}$ & $19,02 \frac{\mathrm{W}}{\mathrm{m}^{2} \cdot \mathrm{K}}$ \\
\hline 5 & $\Delta T_{L M}$ & $33,86 \mathrm{~K}$ & $33,94 \mathrm{~K}$ \\
\hline 6 & $\mathrm{q}$ & $102,68 \mathrm{Watt}$ & $120,2 \mathrm{Watt}$ \\
\hline 7 & $\mathrm{NTU}$ & 11,36 & 13,27 \\
\hline 8 & $\varepsilon$ & $82,4 \%$ & $83,2 \%$ \\
\hline
\end{tabular}


Pada proses pemanasan dengan temperatur susu masuk pemanas $\left(T_{c i}\right)$ sebesar $30^{\circ} \mathrm{C}$ dan temperatur susu keluar pemanas $\left(T_{c o}\right)$ sebesar $90^{\circ} \mathrm{C}$ menghasilkan heat transfer (q) sebesar 101,7 watt dengan efektivitas ( $(\varepsilon)$ sebesar $83,6 \%$. Sedangkan pada proses pemanasan dengan temperatur susu masuk pemanas $\left(T_{c i}\right)$ sebesar $30^{\circ} \mathrm{C}$ dan temperatur susu keluar pemanas $\left(T_{c o}\right)$ sebesar $96,9^{\circ} \mathrm{C}$ menghasilkan heat transfer (q) sebesar 76,68 watt dengan efektivitas $(\varepsilon)$ sebesar $83,7 \%$. Perbedaan efektivitas $(\varepsilon)$ sebesar $0,1 \%$ karena heat transfer (q) yang dihasilkan berbeda. Perhitungan heat transfer (q) diperoleh dari perhitungan LMTD (Log Mean Temperature Difference) yang berbeda pada masing - masing variabel. Besar (Log Mean Temperature Difference) dipengaruhi dari beda temperatur antara temperatur susu masuk $\left(T_{c i}\right)$ dengan temperatur air pemanas $\left(T_{x 1}\right)$ dan antara temperatur susu keluar $\left(T_{c o}\right)$ dengan temperatur air pemanas $\left(T_{x 2}\right)$. Pada temperatur susu masuk pemanas $\left(T_{c o}\right)$ sebesar $90^{\circ} \mathrm{C}$ memiliki (Log Mean Temperature Difference) lebih besar sehingga menghasilkan heat transfer (q) yang besar pula namun berbanding terbalik dengan efektivitasnya $(\varepsilon)$. Semakin besar heat transfer (q) yang dihasilkan maka semakin kecil nilai efektivitasnya ( $(\varepsilon)$.

Sama halnya dengan proses pemanasan, pada proses pendinginan juga terjadi hal yang sama hanya saja yang mempengaruhi besar heat transfer nya (q) yaitu dari overall heat transfer coefficient (U) dengan (Log Mean Temperature Difference) yang hampir sama. Hal ini akan mempengaruhi besar NTU (Number of Transfer Unit) dan selanjutnya mempengaruhi efektivitas $(\varepsilon)$. Semakin besar NTU (Number of Transfer Unit) maka semakin besar efektivitasnya $(\varepsilon)$.

\section{KESIMPULAN}

Dari hasil perhitungan yang telah dilakukan, didapatkan data dari laju perpindahan panas yang berbeda pada setiap variabel suhu yang berbeda. Pada proses pemanasan yang terjadi, semakin besar heat transfer (q) yang dihasilkan maka semakin kecil nilai efektivitasnya $(\varepsilon)$. Sedangkan pada proses pendinginan, semakin besar NTU (Number of Transfer Unit) maka semakin besar efektivitasnya $(\varepsilon)$. Nilai masing - masing heat transfer proses 
pemanasan dan pendinginan adalah sebagai berikut :

1. Pada proses pemanasan dengan $T c_{o}=90^{\circ} \mathrm{C}$ menghasilkan heat transfer sebesar dan efektivitas sebesar $83,6 \%$, lebih rendah $0,1 \%$ dari $T c_{o}=94^{\circ} \mathrm{C}$ yang menghasilkan heat transfer sebesar 76,68 dan efektivitas sebesar $83,7 \%$.

2. Pada proses pendinginan dengan $T h_{o}=26,5^{\circ} \mathrm{C}$ menghasilkan heat transfer sebesar dan efektivitas sebesar 82,4\%, lebih rendah $0,8 \%$ dari $T h_{o}=31,3^{\circ} \mathrm{C}$ yang menghasilkan heat transfer sebesar 120,2 dan efektivitas sebesar $83,2 \%$.

\section{SARAN}

Perhitungan heat transfer pada proses pasteurisasisusu ini belum sepenuhnya sempurna. Hal ini dikarenakan masih banyak parameter yang tidak diikutkan dalam perhitungan, seperti factor plugging, pressure drop, dan yang lainnya. Selain itu, keterbatasan waktu yang ada untuk melakukan percobaan, sehingga membuat data yang dianalisis menggunakan asumsi-asumsi tertentu, seperti pada laju aliran massa pada sisi air pendingin, kapasitas aliran air pendingin, dan faktor koreksi yang mempengaruhi laju perpindahan panas. Sehingga menyebabkan berkurang keakuratan data. Semoga kekurangan-kekurangan tersebut bisa di sempurnakan pada penelitian selanjutnya.

\section{DAFTAR PUSTAKA}

[1] BPS, "Proyeksi Penduduk Indonesia Berdasarkan Hasil Sensus Penduduk 2010”, 2010. [Online]. Available: http://www.bps.go.id/. [Accessed: 10-Nov2019].

[2] G.V. Rachmat, "Prinsip Kerja dari Pasteurisasi Susu dan Pengertiannya", 2018. [Online]. Available: https://id.scribd.com/doc/168607532/Prinsip-KerjaDari-PasteurisasiSusu-Dan-Pengertiannya. [Accessed: 13-Apr-2019].

[3] F.P. Incropera, D.P. DeWitt, T.L. Bergman, and A.S. Lavine, A.S, Fundamentals of Heat and Mass Transfer 6th ed. Amerika Serikat: Wiley and Sons Inc, 2007.

[4] J. Rosul, J. And A. Luthfi, "Rancang Bangun dan Pembuatan Segmen Pendingin untuk Simulator Pasteurisasi Kontinyu dan Karakterisasi 
Mikrobiologi pada Susu Sapi Segar pada HTST (High Temperature Short Time)," Politeknik Negeri Bandung, 2012

[5] N. L. E. Wahyuni, "Penentuan Waktu Tinggal Optimum Pasteurisasi Susu Dengan Plate Heat Exchanger, 2017. [Online]. https://docplayer.info/43354388-Penentuan-waktu-tinggal-optimumpasteurisasi-susu-dengan-plate-heat-exchanger.html [Accessed: 02-Jan-2020]. 